\title{
Bmis Have Different Effects on the Prevalence of OSA in Copd Patients: A Multicenter Cross-sectional Study
}

\author{
Mengqing Xiong \\ Renmin Hospital of Wuhan Univesity
}

\section{Zhiling Zhao}

Beijing Chaoyang Hospital, Capital Medical School

\section{Qingrong Nie}

Liangxiang Hospital of Yanjing Medical College

\section{Zhihong Shi}

The First Affiliated Hospital of Xian Jiaotong University

\section{Bin Wu}

Affiliated Hospital of Guangdong Medical University

\section{Yan Song}

Renmin Hospital of Wuhan University

\section{Xin He}

Renmin Hospital of Wuhan University

\section{Mengmei Wang}

Renmin Hospital of Wuhan University

Ke Hu ( $\square$ huke-rmhospital@163.com)

Renmin Hospital of Wuhan University https://orcid.org/0000-0001-9862-7239

\section{Research}

Keywords: BMI, OSA, COPD, risk, model

Posted Date: July 12th, 2021

DOl: https://doi.org/10.21203/rs.3.rs-688417/v1

License: (c) (i) This work is licensed under a Creative Commons Attribution 4.0 International License. Read Full License 


\section{Abstract}

\section{Background}

Obstructive sleep apnea (OSA) is prevalent in chronic obstructive pulmonary disease (COPD). Underweight and overweight have paradoxical effect on COPD prognosis, while obesity is a risk factor for OSA. We aimed to examine the association between BMls and OSA risk in COPD patients.

\section{Methods}

This cross-section study included 1637 COPD subjects in the final analysis. BMI was classified into different groups. OSA was defined as varying severity by AHI. The associations between BMls and risks of diverse severity of OSA were examined.

Results

For varying severity of OSA, obesity associated with higher risk, while normal weight group associated with lower risk; overweight had no differences and underweight group had lower risk of moderate-tosevere OSA. Compared with normal weight, for OSA, the overweight group showed a trend of high risk whereas the underweight group indicated a higher risk (OR 1.424, 95\% Cl 1.015-1.988) (multivariable adjusted). BMI exhibited a J-shaped association with OSA; the risk for OSA was relatively flat at BMIs of $20-24 \mathrm{~kg} / \mathrm{m}^{2}$ and above or below the risk increased (P for non-linearity 0.0057 ); for severe OSA, the plot depicted a S-shaped relation, the risk reached the lowest around $24 \mathrm{~kg} / \mathrm{m}^{2}$ and then increased thereafter (P for non-linearity 0.0200).

\section{Conclusions}

In COPD population, for various severity of OSA, obesity is a firmly risk factor, overweight not influence the risk, while normal weight associate with lower risk; compared with normal weight, underweight increased the risk for OSA; BMI had a J-shaped association with OSA and a S-shaped with severe OSA.

\section{Background}

Chronic obstructive pulmonary disease (COPD) and obstructive sleep apnea (OSA) are both highly prevalent; the concurrence of these diseases called the overlap syndrome (OVS) ${ }^{1}$ COPD is a public health issue due to the related morbidity, disability and mortality, which affects $13.7 \%$ of Chinese people aged 40 years or older and is the third leading cause of death. ${ }^{2,3}$ OSA, characterized by repetitive upper airway collapse during sleep, is related to many adverse health conditions that decrease quality of life and survival. ${ }^{4-6}$ Moreover, OSA is a major comorbidity of COPD that increases the rates of COPD exacerbation, hospital readmission and mortality. 2,7-10

Studies show body mass index (BMI) has a J-shaped, U-shaped or inverse association with prognosis of respiratory diseases. ${ }^{11,12}$ Low BMI is associated with worse outcomes, and overweight/obesity has a 
protective effect in COPD patients, ${ }^{13,14}$ while obesity is a well-known risk factor for OSA. ${ }^{15-17}$ However, studies about BMI in OVS patients are blurred, and it is unclear whether the risk of OSA starts to increase with overweight or just with obesity and whether underweight influences risk. It is unclear either if the risk for varying severity of OSA differ between different BMI categories. We hypothesized that BMI has a nonlinear association with risk of OSA in COPD patients.

We aimed to examine the association between BMls and the risk of varying severity of OSA in COPD patients in detail.

\section{Methods}

\section{Study design and ethics}

This was an observational, multicenter study of COPD patients, registered in ClinicalTrials.gov (Clinical Trials ID: NCT 03182309). The protocol was reviewed and approved by the Ethics Committee of Renmin Hospital of Wuhan University (No. 2017K-C014) and the trail was conducted in compliance with the Declaration of Helsinki.

\section{Participants and flow}

From Jan 2017 to Jan 2020, 1911 patients with COPD who met the inclusion and exclusion criteria were enrolled as study candidates from five Chinese tertiary hospitals. The inclusion criteria were as follows: subjects aged at least 40 years old with a diagnosis of COPD conforming to the GOLD guidelines. Candidates were excluded based on the following: 1) those who were less than 40 years old or pregnant; 2) patients with evidence of bronchial asthma, bronchiectasis, pulmonary fibrosis, intratracheal neoplasms, destructive sequelae of tuberculosis, etc. ; 3 ) patients with other diseases affecting survival, such as neoplastic diseases, renal insufficiency, or acute myocardial infarction; 4) those with a history of stroke, heart failure, neuromuscular disease, cognitive impairment or other mental or psychological diseases that would prevent completion of pulmonary function tests questionnaires or polysomnography (PSG); and 5) those who had other sleep disorders, such as obesity hypoventilation syndrome.

Every subject enrolled in this study was informed about the purpose and process of the study, and written consent forms were signed. Baseline information and demographics were obtained from patients' and their electronic medical records. The questionnaire survey was administered after subjects were enrolled and lung function tests or PSG were performed while patients were relatively stable.

Data were exported from the electronic database of this program. The study flow diagram was shown in Figure 1. Subjects who dropped out before their data were input into the electronic system were excluded from this prospective study. Some subjects were excluded for the following reasons: 128 patients were unable to complete lung function tests for a severe condition or refused, 161 could not tolerate or refused to perform PSG (including 77 patients did not complete lung function tests), and 62 had unqualified PSG data. Finally, a total of 1637 subjects were included in the analyses. 


\section{Lung Function Test}

Lung function tests were performed under the guidance of professional technicians by using a spirometer (MasterScreenBody, Jaeger, Germany). The diagnosis and severity of COPD were assessed according to Global Initiative for Chronic Obstructive Lung Disease (GOLD) guidelines. ${ }^{2}$ Those with a ratio of forced expiratory volume in 1 second $\left(\mathrm{FEV}_{1}\right)$ /forced vital capacity $(\mathrm{FVC})$ in a post-bronchodilator less than $70 \%$ were diagnosed with COPD, and airflow limitation was classified based on the value of $\mathrm{FEV}_{1}$ in the post-bronchodilator.

\section{PSG and OSA Diagnostic Criteria}

All subjects with confirmed COPD underwent assessment of sleep events with a multichannel sleep diagnostic system (SOMNOscreen Plus Tele PSG, SOMNOmedic GmbH, Germany) in the sleep laboratory overnight monitoring. All tracings were manually scored according to the American Academy of Sleep Medicine criteria. ${ }^{18}$ Those who experienced apnea-hypopnea index $(\mathrm{AHI}) \geq 5$ events/h during sleep were

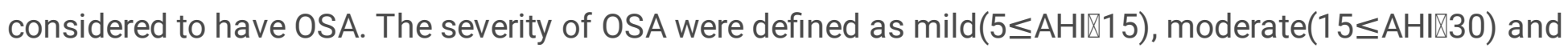
severe $(\mathrm{AHI} \geq 30){ }^{18}$

\section{Statistical Analyses}

Patients were divided into OVS and COPD-only groups. Data are presented as the mean \pm standard deviation (SD) for continuous variables and frequency or percentages for categorical variables. Baseline characteristics and demographics were compared between the two groups. BMI was sort into dichotomous variables like underweight group and non-underweight group, normal weight group and nonnormal weight group, overweight group and non-overweight group, obese group and nonobese group or classified into four categories according to Chinese criteria: ${ }^{19}$ underweight $\left(B M \mathrm{~K}<18.5 \mathrm{~kg} / \mathrm{m}^{2}\right)$, normal weight (BMI 18.5-23.9 kg/m²), overweight (BMl $24-27.9 \mathrm{~kg} / \mathrm{m}^{2}$ ) and obese (BMl $\geq 28 \mathrm{~kg} / \mathrm{m}^{2}$ ). The severity of OSA was defined by AHI. Independent t-tests were used for normally distributed continuous variables, the Mann-Whitney U-test for nonnormally distributed continuous variables, and the $\chi^{2}$ test for categorical variables. Logistic regressions were conducted to examine the associations between BMI categories and risk for different severity of OSA. Collinearity between independent variables was also assessed. Candidate variables which were considered clinically relevant or with a $p$ value $\mathbb{0} 0.1$ on univariate analysis were entered into multivariable model. Variables for inclusion were carefully chosen, given the number of events available, to ensure parsimony of the final model. The crude model had no adjustment. Model 1 was adjusted for $\mathrm{FEV}_{1} \%$ pred. Model 2 was a fully adjusted model that adjusted for sex, age, job, education level, smoking status, alcohol consumption, $\mathrm{FEV}_{1} \%$ pred, and hypertension. In the BMI categories and OSA analyses, the normal weight (BMI 18.5-23.9 kg/ $\mathrm{m}^{2}$ ) group was taken as the reference category. To further investigate the relationship between $\mathrm{BMI}$ and OSA, the restricted cubic splines in a fully adjusted model (confounders were same with Model 2) with five knots were performed to flexibly model and visualize the relation of BMI with OSA. A p value (two tailed) of less than 0.05 was 
considered statistically significant. Analyses were performed using SPSS 24.0 (IBM, Armonk NY, USA) and $\mathrm{R}$ (version 4.0 .2 basic).

\section{Results}

\section{Baseline and Demographic Characteristics}

Table1 showed baseline characteristics and demographics of the participates. According to the results of PSG, 1076 (65.7\%) subjects were divided into the OVS group, and the others were COPD-only group. In this group of COPD patients, male patients accounted for over $80 \%$, and the proportion was even higher in the OVS group than the COPD only group ( $85.5 \%$ vs $81.6 \%, p=0.042)$. The average age of this population was more than 65 years old, and retirees accounted for more than $45 \%$ of the sample. Regarding occupation, office clerks and workers were more common in the OVS group (11.5\% vs $6.1 \%)(11.6$ vs 8.9$)$ ), while farmers were more common in the COPD-only group (31.0\% vs $22.6 \%)$. The OVS group had higher rates of college or higher education, but the COPD-only group had higher rates of primary school or below education. Current smoking (56.3\% vs $48.0 \%)$ and alcohol consumption (35.5\% vs $8.6 \%$ ) were more prevalent in the OVS cohort, and more COPD-only patients quit smoking (32.4\% vs $24.5 \%$ ) or drinking alcohol ( $27.5 \%$ vs $7.9 \%$ ). Regarding BMI, the OVS group had a higher proportion of overweight $(29.4 \%$ vs $27.3 \%)$ or obese $(17.4 \%$ vs $8.4 \%)$ individuals, and COPDonly patients had a higher proportion of normal weight individuals (51.9\% vs $41.4 \%$ ). Spirometry tests showed that the OVS group had better lung function with a higher proportion of GOLD1 or COLD2 subjects, while the COPD-only group had more severe cases. Apparently, the OVS group had more characteristics indicating severe sleep-disordered breathing, such as higher $\mathrm{AHI}$, longer TS90\%, and lower nadir $\mathrm{SaO}_{2}$ and average $\mathrm{SaO}_{2}$, during the full-night PSG. There were no significant differences in age, Modified Medical Research Council (mMRC) dyspnea scale score and COPD Assessment Test (CAT) score. A higher prevalence of hypertension could be found in OVS patients, but no difference was found in coronary heart disease, diabetes mellitus or cerebrovascular disease.

\section{The distribution of diverse severity of OSA in different categories of BMI}

Table 2 showed the prevalence of OSA and diverse severity of OSA in different BMI categories. BMI was sort into dichotomous variables like underweight group and non-underweight group, normal weight group and non-normal weight group, overweight group and non-overweight group, obese group and non-obese group, or classified as underweight, normal weight, overweight group and obese group like mentioned in methods. OSA occurred differently in various BMls with $\mathrm{p} \otimes 0.001$. In obese group, OSA was very common with a prevalence of $79.9 \%$, while in normal weight group had a high prevalence of no OSA with a rate of $39.5 \%$. There were no differences in the prevalence of OSA for underweight or overweight group ( $\mathrm{p} \otimes 0.05)$. Varying severity of OSA also occurred differently in BMI categories ( $\mathrm{p} \otimes 0.001)$. The prevalence of no OSA to severe OSA distributed differently in underweight, normal weight and obese group with $p \leq 0.001$, but there were no significantly difference in overweight group with a p value of 0.724 . Underweight group had high prevalence of mild OSA with $46.2 \%$, and obese group a high rate of moderate to severe OSA. 


\section{The risks for different degree of OSA in dichotomized BMls of COPD patients}

Table 3 displayed the risks for diverse severity of OSA in different BMI categories. BMI was sort into dichotomous variables like mentioned above, and the risks for OSA, moderate-to-severe OSA and severe OSA were analysed respectively. Compared with non-underweight group, the underweight group had lower risk for moderate-to severe OSA no matter confounders adjusted or not with the value of OR $(95 \% \mathrm{Cl})$ was $0.633(95 \% \mathrm{Cl} 0.428-0.938$ ) in the fully adjusted model (Model 2); the underweight group also had lower risk for severe OSA in Crude model (no adjustment), but after $\mathrm{FEV}_{1} \%$ pred adjusted (Model 1) or confounders fully adjusted (Model 2 ) the trend became not significantly ( $\mathrm{p} \otimes 0.05$ ). When sorted BMI into normal weight group and non-normal weight group, the risk of having OSA, moderate-to-severe OSA or severe OSA were lower for normal weight COPD patients with OR $\ 1$ and $\mathrm{p} \otimes 0.05$ in crude or adjusted models. Compared with non-overweight group, overweight group had no differences for the risks of various severity of OSA with $\mathrm{p} \otimes 0.05$. As to obese group, compared with non-obese group, the risk was

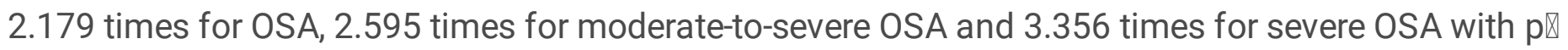
0.001 after multivariate adjusted (Model 2).

\section{The risks for various severity of OSA in BMI category of COPD patients}

Table 4 presented the risk for various severity of OSA according to BMls using normal weight group as reference. BMI was classified into four categories: underweight $\left(B M K 18.5 \mathrm{~kg} / \mathrm{m}^{2}\right)$, normal weight (BMI:18.5-23.9 kg/m²), overweight (BMl: $24-27.9 \mathrm{~kg} / \mathrm{m}^{2}$ ) and obese (BMI $\geq 28 \mathrm{~kg} / \mathrm{m}^{2}$ ). BMl category was significantly associated with varying severity of OSA with $\mathrm{p}$ for trend less than 0.05 in crude or adjusted models. Using normal weight as the reference group, the obese group had higher risk for OSA(OR 2.468, 95\% Cl 1.704-3.574), moderate-to-severe OSA (OR 2.642, 95\% Cl 1.902-3.670) and severe OSA (OR 3.741, $95 \% \mathrm{Cl}$ 2.463-5.682) after confounders fully adjusted (Model 2); the overweight group had 1.348 times risk for OSA in Crude, while after $\mathrm{FEV}_{1} \%$ pred adjusted (Model 1) or multivariable adjusted (Model 2) it just remained a trend but not significantly with a $p$ value of 0.087 or 0.079 ; for moderate-to-severe OSA there were no difference and for severe OSA it existed a trend of high risk with a $p$ value of 0.076 , but the trend vanished in Model 1 or Model 2; unexpectedly, the underweight group indicated a trend for higher risk for

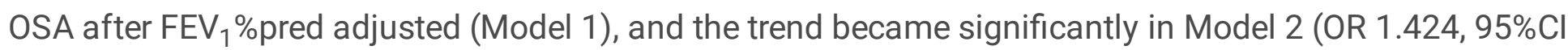
1.015-1.988); the underweight group showed a lower risk for moderate-to-severe OSA(OR $0.626,95 \% \mathrm{Cl}$ 0.421-0.931) in Crude model and remained a trend in Model 1 but became not significantly in Model 2.; and there was no difference in the risk for severe OSA (pष0.05).

\section{The relations of varying severity of OSA and BMI in COPD patients}

We used the restricted cubic spline models with five knots to flexibly model and visualize the associations of BMI with varying severity of OSA in COPD patients (Figure 2). The models were multivariable adjusted that the confounders in lines with Model 2 (Table 3 and Table 4). The plot(A) showed a J-shaped relation between BMI and OSA. The risk for OSA was relatively flat at BMIs in the range of $20-24 \mathrm{~kg} / \mathrm{m}^{2}$ and then started to increase afterwards; interestingly, a BMI below $20 \mathrm{~kg} / \mathrm{m}^{2}$ was also associated with increased 
risk, although the magnitude varied ( $P$ for non-linearity 0.0057). For moderate-to-severe OSA, there was a $J$-shaped association but not significantly with the $p$ value for nonlinearity of 0.2024 (plot B). As to severe OSA, the plot(C) displayed a S-shaped association between BMI and OSA, the risk reached the lowest around $24 \mathrm{~kg} / \mathrm{m}^{2}$ and then increased thereafter ( $P$ for non-linearity 0.0200 ).

\section{Discussion}

A total of 1637 COPD patients were assessed, and the prevalence of OSA, moderate OSA and severe OSA was $65.7 \%, 17.6 \%$ and $12.0 \%$ respectively. A meta-analysis by Shawon and colleagues estimated that among COPD patients, OSA had a prevalence ranging from 2 to $65.9 \% .{ }^{9}$ These data are suggested that OSA is prevalent in COPD patients. Although males accounted for more than $80 \%$ of the cohort, the OVS group had more male patients than the COPD-only group, showing that males were more likely to develop OSA even in the COPD cohort. In addition, the OVS group had more office clerks or workers, which may correspond to more current smoking and alcohol consumption, higher BMI and larger neck circumference, which are established risk factors for OSA. 6,15,20-24 Cigarette smoking was very popular in these COPD patients. There were fewer than $20 \%$ patients who never smoked, and the proportions of current smokers among OVS patients and COPD only patients were $56.3 \%$ and $48.0 \%$, respectively. Considering the high prevalence of COPD or OVS and the related disability, disease and economic burden, smoking prevention and cessation are of vital importance. The two groups had no significant difference in age, mMRC dyspnea scale score and CAT score, which may indicate that they had a similar clinical status when enrolled in this study. Spirometry and PSG were performed while the patients were relatively stable. Even so, the COPD-only cohort had poorer lung function, and the OVS group had worse nocturnal desaturation accompanied by more hypertension. These characteristics were also in line with our preliminary analysis. ${ }^{25}$ This finding may confirm that OSA indeed contributed to poor outcomes of COPD, as reported. ${ }^{7}$

Our study showed varying degrees of OSA distribute differently in different BMIs. Underweight COPD patients complicated with more mild OSA; normal weight group had less OSA population, while obese group had more OSA individual especially moderate and severe OSA; whereas, compared with nonoverweight group, overweight group had no differences in the prevalence of varying severity of OSA. In logistic analyses, Crude model was no adjustment; Model 1 adjusted $\mathrm{FEV}_{1} \%$ pred; confounders which clinically relevant like age, or with a $p$ value $\mathbb{0 . 1}$ on univariate analysis like sex, age, job, education, smoking, alcohol consumption, $\mathrm{FEV}_{1} \%$ pred, and high blood pressure were forced into the multivariate model (Model 2). Compared with non-obese group, the obese group had higher risk for different severity of OSA, while normal weight group had lower risk than non-normal group in crude or adjusted models and there were no differences in overweight and non-overweight group. Underweight group had lower risk for moderate-to-severe OSA. When using normal weight as a reference group, the obese group had higher risk for various severity of OSA; the overweight group had higher risk for OSA in crude, while it just remained a trend but not significantly in Model 1or Model 2; whereas, the underweight group indicated a trend of higher risk for OSA in Model 1, and the trend became significantly in Model 2 and showed a lower risk for 
moderate-to-severe OSA in Crude. These data indicated that for diverse severity of OSA, obesity is a firm risk factor even in COPD population, while normal weight group associated with lower risk. Overweight may not influence the risk for varying severity of OSA, while took normal weight as reference it showed a trend for high risk for OSA. Underweight showed a lower risk for moderate to severe OSA, while compared with normal weight it increased the risk for OSA but not for moderate or severe OSA. They support the recommendation to maintain a healthy weight for the prevention of chronic disease like reported. ${ }^{12}$

We further investigated the nonlinear relationship of BMI with OSA in this sample using restricted cubic models. The plot showed that BMI had a J-shaped association with OSA in COPD patients, with the lowest risk in the range of $20-24 \mathrm{~kg} / \mathrm{m}^{2}$ and above or below the risk increased. For severe OSA, the plot depicted a S-shaped association, which reached the lowest risk about $24 \mathrm{~kg} / \mathrm{m}^{2}$ and then increased thereafter. They can be supported by the logistic regression analyses mentioned above. Studies have reported that BMI has a J-shaped, U-shaped or inverse association for adverse outcomes of respiratory diseases. ${ }^{11-13}$ A population-based cohort study of 3.6 million UK adults showed that BMI had a J-shaped association with respiratory diseases, with the nadir of risk occurring in the range of $21-25 \mathrm{~kg} / \mathrm{m}^{2} .{ }^{11}$ Therefore, it makes sense that a healthy weight plays a vital role in the prognosis of COPD. Follow-up studies and meta-analyses indicated that among COPD patients, low BMI was associated with higher mortality. ${ }^{26-28}$ A National Survey from Korea showed that low BMI contributed to COPD development and mortality, while normal or higher than normal weight had a protective effect. ${ }^{29}$ However, a large, randomly selected population study by Landbo et al. ${ }^{30}$ suggested that obesity had a protective effect in severe COPD patients, but in those with mild to moderate disease, obesity was associated with a worse prognosis. Moreover, a follow-up study of 968 COPD patients enrolled from the hospital reported that after adjusting for confounders, including GOLD stage, the optimal BMI with the lowest risk for death was in the overweight category: $25.09-26.56 \mathrm{~kg} / \mathrm{m}^{2} .{ }^{31} \mathrm{~A}$ study in the general population suggested that BMI $24.4 \mathrm{~kg} / \mathrm{m}^{2}$ was a risk factor for COPD in OSA patients, and being overweight but not obese likely protects moderate to severe OSA patients from the risk of COPD. ${ }^{32}$ Therefore, it is possible that a healthy weight or overweight may protect against the development of OSA in patients with COPD and underweight group may trend to have risk of OSA contributed to poorer outcomes. This hypothesis, which is mainly speculative, needs further study. To our knowledge, no survey has evaluated classified BMI with the risk of OSA in a COPD cohort.

Notably, OSA is highly prevalent in obese individuals and has been investigated extensively. ${ }^{4,20,33}$ Although few studies have investigated the prevalence of OSA in underweight people, a Japanese study of 3659 OSA patients from 11 hospitals showed that underweight patients exhibited a higher AHI than normal weight patients. ${ }^{34} \mathrm{~A}$ recent survey showed that lower BMI was a risk factor for OSA in elderly Thai hypertensive patients. ${ }^{35}$ In this study, we hypothesize that several factors might explain the J-shaped association between low BMI and OSA but not moderate or severe OSA. First, COPD patients with low BMI may have poor nutritional status and more body wasting, which results in reductions in ventilation and activities of upper airway muscle function and increases upper airway resistance. ${ }^{36-38}$ Second, the 
position during sleep also impacts the upper airway. A study of diagnosed OSA patients who underwent drug-induced sleep endoscopy showed that the prevalence of tongue-base obstruction in patients with low BMI was $100 \%$ in the supine position. ${ }^{39}$ Third, narrowing of the upper airway can occur due to inflammation. Cigarette smoking-induced upper airway inflammation likely contributes to OSA. Stokes et al. showed that overweight/obese individuals are less likely to smoke than their normal weight counterparts. ${ }^{40}$ Similar behavior may be present in COPD patients with a low BMI. OSA also appears to exacerbate lower airway inflammation..$^{41}$ In addition, inhaled corticosteroids may contribute to OSA by causing upper airway myopathy or extrapulmonary inflammation, which may impair upper airway reflexes or neuromuscular responses. ${ }^{42-44}$ Finally, the extent of emphysema and chronic bronchitis influence the occurrence of OSA. Studies show that lung hyperinflation against the risk of OSA by lowering the critical closing pressure of the upper airway, while chronic bronchitis predisposes patients to a higher risk of OSA due to lower respiratory drive and peripheral fluid retention in the cor pulmonale. ${ }^{45-47}$ In fact, a majority of COPD patients have a mixture of emphysema and chronic bronchitis, and the risk of OSA is associated with protective and promoting factors in COPD patients. Therefore, it may be reasonable that BMI had a Jshaped association with OSA, with the lowest risk in the range of $20-24 \mathrm{~kg} / \mathrm{m}^{2}$. Unintentional weight loss should perhaps be considered a deleterious factor rather than obesity as a protective one. Maintaining a healthy weight should be recommended. This recommendation should attach importance for chronic disease especially wasting disease like COPD. Intervention and strategies to promote a healthy weight may improve the status of the population.

To the best of our knowledge, this is the first study to extensively examine the role of BMls in the risk of OSA in COPD patients and explore nonlinearity. First, our study is a national multicenter, cross-sectional and prospective survey with 1637 COPD cases included in the final analysis. Second, our data not only indicated the relationship of BMI with the risk of OSA in COPD patients but also examined different BMI categories and different severity of OSA. Third, for the first time, the nonlinear relationship of BMI with OSA in COPD subjects was flexibly modeled and visualized by using the restricted cubic spline models. Finally, BMI is an easily available parameter that carries important information for clinical assessment and risk stratification. For the exacerbation of chronic wasting disease, patients may cannot complete some tests. BMI may indicate a potential to identify patients at risk of OSA and provide therapeutic information for clinicians.

There are some limitations in this study. First, this was a multicenter, cross-sectional study, the data may be heterogenous and potential recall bias cannot be excluded. Second, patients were enrolled from inpatient or outpatient clinics, and although lung function tests and PSG were performed under the guidance of professional technicians when subjects were in a stable state, the patients may be somewhat different from the general population. However, the project leaders, main researchers and specialists in related fields engaged in discussion and agreed on these issues before the study was conducted; the unified criterion, standardized instruments, standardized operations, standardized projects and processes and relatively large sample could minimize bias and heterogeneity. Finally, this was a cross-section study 
showed the association between OSA and BMI in COPD cohort; in the future, prospective and follow-up studies focusing on the prognosis of low BMI and BMI category with OSA in COPD patients are needed.

\section{Conclusions}

OSA is a frequent finding in COPD patients and may contribute to poor outcomes. In COPD population, obesity is a firmly risk factor for OSA, moderate-to-severe OSA or severe OSA, while normal weight group had lower risk for these degrees of OSA; overweight may not influence the risk for varying severity of OSA, while took normal weight as reference it showed a trend of high risk for OSA; underweight showed a lower risk for moderate to severe OSA, while compared with normal weight it increased the risk for OSA but not for moderate or severe OSA. BMI has a J-shaped relation with OSA for COPD subjects; the risk for OSA was relatively flat at BMls in the range of $20-24 \mathrm{~kg} / \mathrm{m}^{2}$ and above or below the risk increased; for severe OSA, the plot depicted a S-shaped association, the risk reached the lowest around $24 \mathrm{~kg} / \mathrm{m}^{2}$ and then increased thereafter.

\section{Declarations}

Ethics approval and consent to participate: The protocol of this study was reviewed and approved by the Ethics Committee of Renmin Hospital of Wuhan University (No.2017K-C014). The trial was conducted in compliance with the Declaration of Helsinki and every patient included in this study was informed about the purpose of the study and written consent was signed.

Trial registration[This study was registered in ClinicalTrials.gov (Clinical Trials ID: NCT 03182309).

Consent for publication: Agreed.

Availability of data and materials: This project is still going on and our present study is one part of this project. Thus, these data cannot available till the program is fully completed, but if requested data will be made available.

Conflict of interests: The authors declare they have no conflict of interest.

Funding: This work was supported by grants from the National Natural Science Foundation of China (No. 81970082) and the National Key Research and Development Program of China (No. 2016YFC1304403).

Acknowledgements: We thanked the funding and our colleagues who contributed to this study.

\section{References}

1. Malhotra A, Schwartz AR, Schneider H, et al. Research Priorities in Pathophysiology for Sleepdisordered Breathing in Patients with Chronic Obstructive Pulmonary Disease. An Official American Thoracic Society Research Statement. American journal of respiratory and critical care medicine 2018;197:289-99. 
2. Vogelmeier CF, Criner GJ, Martinez FJ, et al. Global Strategy for the Diagnosis, Management, and Prevention of Chronic Obstructive Lung Disease 2017 Report. GOLD Executive Summary. American journal of respiratory and critical care medicine 2017;195:557-82.

3. Wang $\mathrm{C}, \mathrm{Xu} \mathrm{J}$, Yang $\mathrm{L}$, et al. Prevalence and risk factors of chronic obstructive pulmonary disease in China (the China Pulmonary Health [CPH] study): a national cross-sectional study. Lancet (London, England) 2018;391:1706-17.

4. Lim DC, Pack Al. Obstructive Sleep Apnea: Update and Future. Annual review of medicine 2017;68:99112.

5. Povitz M, Bolo CE, Heitman SJ, Tsai WH, Wang J, James MT. Effect of treatment of obstructive sleep apnea on depressive symptoms: systematic review and meta-analysis. PLoS medicine 2014;11:e1001762.

6. Young T, Peppard PE, Gottlieb DJ. Epidemiology of obstructive sleep apnea: a population health perspective. American journal of respiratory and critical care medicine 2002;165:1217-39.

7. McNicholas WT. COPD-OSA Overlap Syndrome: Evolving Evidence Regarding Epidemiology, Clinical Consequences, and Management. Chest 2017;152:1318-26.

8. Marin JM, Soriano JB, Carrizo SJ, Boldova A, Celli BR. Outcomes in patients with chronic obstructive pulmonary disease and obstructive sleep apnea: the overlap syndrome. American journal of respiratory and critical care medicine 2010;182:325-31.

9. Shawon MS, Perret JL, Senaratna CV, Lodge C, Hamilton GS, Dharmage SC. Current evidence on prevalence and clinical outcomes of co-morbid obstructive sleep apnea and chronic obstructive pulmonary disease: A systematic review. Sleep medicine reviews 2017;32:58-68.

10. Naranjo M, Willes L, Prillaman BA, Quan SF, Sharma S. Undiagnosed OSA May Significantly Affect Outcomes in Adults Admitted for COPD in an Inner-City Hospital. Chest 2020;158:1198-207.

11. Bhaskaran K, Dos-Santos-Silva I, Leon DA, Douglas IJ, Smeeth L. Association of BMI with overall and cause-specific mortality: a population-based cohort study of 3.6 million adults in the UK. The lancet Diabetes \& endocrinology 2018;6:944-53.

12. Lee DH, Keum N, Hu FB, et al. Predicted lean body mass, fat mass, and all cause and cause specific mortality in men: prospective US cohort study. BMJ (Clinical research ed) 2018;362:k2575.

13. Yang $L$, Zhou M, Smith $M$, et al. Body mass index and chronic obstructive pulmonary diseaserelated mortality: a nationally representative prospective study of 220,000 men in China. International journal of epidemiology 2010;39:1027-36. 
14. Sun $\mathrm{Y}$, Milne $\mathrm{S}$, Jaw JE, et al. BMI is associated with FEV(1) decline in chronic obstructive pulmonary disease: a meta-analysis of clinical trials. Respiratory research 2019;20:236.

15. Wall H, Smith C, Hubbard R. Body mass index and obstructive sleep apnoea in the UK: a crosssectional study of the over-50s. Primary care respiratory journal : journal of the General Practice Airways Group 2012;21:371-6.

16. Schwartz AR, Patil SP, Laffan AM, Polotsky V, Schneider H, Smith PL. Obesity and obstructive sleep apnea: pathogenic mechanisms and therapeutic approaches. Proceedings of the American Thoracic Society 2008;5:185-92.

17. Romero-Corral A, Caples SM, Lopez-Jimenez F, Somers VK. Interactions between obesity and obstructive sleep apnea: implications for treatment. Chest 2010;137:711-9.

18. Berry RB, Budhiraja R, Gottlieb DJ, et al. Rules for scoring respiratory events in sleep: update of the 2007 AASM Manual for the Scoring of Sleep and Associated Events. Deliberations of the Sleep Apnea Definitions Task Force of the American Academy of Sleep Medicine. Journal of clinical sleep medicine: JCSM : official publication of the American Academy of Sleep Medicine 2012;8:597-619.

19. Zhou BF. Predictive values of body mass index and waist circumference for risk factors of certain related diseases in Chinese adults-study on optimal cut-off points of body mass index and waist circumference in Chinese adults. Biomedical and environmental sciences : BES 2002;15:83-96.

20. Senaratna CV, Perret JL, Lodge CJ, et al. Prevalence of obstructive sleep apnea in the general population: A systematic review. Sleep medicine reviews 2017;34:70-81.

21. Black JK, Whittaker AC, Balanos GM. Undiagnosed Obstructive Sleep Apnea and Physical Activity in Older Manual Workers. Journal of aging and physical activity 2019;27:293-9.

22. Chung F, Subramanyam R, Liao P, Sasaki E, Shapiro C, Sun Y. High STOP-Bang score indicates a high probability of obstructive sleep apnoea. British journal of anaesthesia 2012;108:768-75.

23. Patel SR. Obstructive Sleep Apnea. Annals of internal medicine 2019;171:Itc81-itc96.

24. Johnson DA, Guo N, Rueschman M, Wang R, Wilson JG, Redline S. Prevalence and correlates of obstructive sleep apnea among African Americans: the Jackson Heart Sleep Study. Sleep 2018;41.

25. Xiong MQ, Hu WH, Hu K, et al. [Analysis of risk factors and consequences for concurrent obstructive sleep apnea in chronic obstructive pulmonary disease patients]. Zhonghua jie he he hu xi za zhi $=$ Zhonghua jiehe he huxi zazhi $=$ Chinese journal of tuberculosis and respiratory diseases 2019;42:832-7.

26. Schols AM, Slangen J, Volovics L, Wouters EF. Weight loss is a reversible factor in the prognosis of chronic obstructive pulmonary disease. American journal of respiratory and critical care medicine 
27. Celli BR, Cote CG, Marin JM, et al. The body-mass index, airflow obstruction, dyspnea, and exercise capacity index in chronic obstructive pulmonary disease. The New England journal of medicine 2004;350:1005-12.

28. Yamauchi $\mathrm{Y}$, Hasegawa $\mathrm{W}$, Yasunaga $\mathrm{H}$, et al. Paradoxical association between body mass index and in-hospital mortality in elderly patients with chronic obstructive pulmonary disease in Japan. International journal of chronic obstructive pulmonary disease 2014;9:1337-46.

29. Park HJ, Cho JH, Kim HJ, Park JY, Lee HS, Byun MK. The effect of low body mass index on the development of chronic obstructive pulmonary disease and mortality. Journal of internal medicine 2019;286:573-82.

30. Landbo C, Prescott E, Lange P, Vestbo J, Almdal TP. Prognostic value of nutritional status in chronic obstructive pulmonary disease. American journal of respiratory and critical care medicine 1999;160:1856-61.

31. Lainscak M, von Haehling S, Doehner W, et al. Body mass index and prognosis in patients hospitalized with acute exacerbation of chronic obstructive pulmonary disease. Journal of cachexia, sarcopenia and muscle 2011;2:81-6.

32. Choi KM, Thomas RJ, Kim J, Lee SK, Yoon DW, Shin C. Overlap syndrome of COPD and OSA in Koreans. Medicine 2017;96:e7241.

33. Young T, Peppard PE, Taheri S. Excess weight and sleep-disordered breathing. Journal of applied physiology (Bethesda, Md : 1985) 2005;99:1592-9.

34. Ohdaira F, Nakamura K, Nakayama H, et al. Demographic characteristics of 3,659 Japanese patients with obstructive sleep apnea-hypopnea syndrome diagnosed by full polysomnography: associations with apnea-hypopnea index. Sleep \& breathing = Schlaf \& Atmung 2007;11:93-101.

35. Sawanyawisuth $\mathrm{K}$, Chindaprasirt J, Senthong V, et al. Lower BMI is a predictor of obstructive sleep apnea in elderly Thai hypertensive patients. Sleep \& breathing = Schlaf \& Atmung 2013;17:1215-9.

36. Schols AM, Broekhuizen R, Weling-Scheepers CA, Wouters EF. Body composition and mortality in chronic obstructive pulmonary disease. The American journal of clinical nutrition 2005;82:53-9.

37. Lenk K, Schuler G, Adams V. Skeletal muscle wasting in cachexia and sarcopenia: molecular pathophysiology and impact of exercise training. Journal of cachexia, sarcopenia and muscle 2010;1:921.

38. Worsnop C, Kay A, Kim Y, Trinder J, Pierce R. Effect of age on sleep onset-related changes in respiratory pump and upper airway muscle function. Journal of applied physiology (Bethesda, Md : 1985) 
39. Woo HJ, Lim JH, Ahn JC, et al. Characteristics of Obstructive Sleep Apnea Patients With a Low Body Mass Index: Emphasis on the Obstruction Site Determined by Drug-Induced Sleep Endoscopy. Clinical and experimental otorhinolaryngology 2020;13:415-21.

40. Stokes A, Preston SH. Smoking and reverse causation create an obesity paradox in cardiovascular disease. Obesity (Silver Spring, Md) 2015;23:2485-90.

41. Wang Y, Hu K, Liu K, et al. Obstructive sleep apnea exacerbates airway inflammation in patients with chronic obstructive pulmonary disease. Sleep medicine 2015;16:1123-30.

42. Teodorescu M, Consens FB, Bria WF, et al. Predictors of habitual snoring and obstructive sleep apnea risk in patients with asthma. Chest 2009;135:1125-32.

43. Teodorescu M, Xie A, Sorkness CA, et al. Effects of inhaled fluticasone on upper airway during sleep and wakefulness in asthma: a pilot study. Journal of clinical sleep medicine : JCSM : official publication of the American Academy of Sleep Medicine 2014;10:183-93.

44. Kimoff RJ. Upperairway myopathy is important in the pathophysiology of obstructive sleep apnea. Journal of clinical sleep medicine : JCSM : official publication of the American Academy of Sleep Medicine 2007;3:567-9.

45. Biselli P, Grossman PR, Kirkness JP, et al. The effect of increased lung volume in chronic obstructive pulmonary disease on upper airway obstruction during sleep. Journal of applied physiology (Bethesda, Md : 1985) 2015;119:266-71.

46. Krachman SL, Tiwari R, Vega ME, et al. Effect of Emphysema Severity on the Apnea-Hypopnea Index in Smokers with Obstructive Sleep Apnea. Annals of the American Thoracic Society 2016;13:112935 .

47. White LH, Bradley TD. Role of nocturnal rostral fluid shift in the pathogenesis of obstructive and central sleep apnoea. The Journal of physiology 2013;591:1179-93.

\section{Tables}

Table 1 Baseline Characteristics and Demographics of the patients 


\begin{tabular}{|c|c|c|c|c|}
\hline Parameter & Total $(\mathrm{n}=1637)$ & $\begin{array}{l}\text { COPD } \\
\text { only }(n=561)\end{array}$ & OVS $(n=1076)$ & $\begin{array}{l}\mathrm{P} \\
\text { Value }\end{array}$ \\
\hline Sex, male, n(\%) & 1378(84.2) & $458(81.6)$ & $920(85.5)$ & 0.042 \\
\hline Age, yr & $65.9 \pm 9.2$ & $65.7 \pm 8.7$ & $66.0 \pm 9.5$ & 0.537 \\
\hline Job, n(\%) & & & & $\begin{array}{l}\square \\
0.001\end{array}$ \\
\hline Unemployment & 132(8.1) & $49(8.7)$ & $83(7.7)$ & \\
\hline Retirement & $755(46.1)$ & $254(45.3)$ & $501(46.6)$ & \\
\hline Office clerk & 158(9.7) & $34(6.1)$ & $124(11.5)$ & \\
\hline Worker & $175(10.7)$ & $50(8.9)$ & $125(11.6)$ & \\
\hline Farmer & $417(25.5)$ & $174(31.0)$ & $243(22.6)$ & \\
\hline Education level, n(\%) & & & & 0.003 \\
\hline Primary school and less & $519(31.7)$ & 197(35.1) & $322(29.9)$ & \\
\hline Middle and high school & $892(54.5)$ & $307(54.7)$ & $585(54.4)$ & \\
\hline College and higher & $226(13.8)$ & $57(10.2)$ & $169(15.7)$ & \\
\hline Smoking states & & & & 0.001 \\
\hline Never & $316(19.3)$ & 110(19.6) & 206(19.1) & \\
\hline Former & $446(27.2)$ & 182(32.4) & $264(24.5)$ & \\
\hline Current & $875(53.5)$ & $269(48.0)$ & $606(56.3)$ & \\
\hline Alcohol consumption, n(\%) & & & & 0.004 \\
\hline Never & $968(59.1)$ & $359(64.0)$ & $609(56.6)$ & \\
\hline Former & 133(8.1) & 154(27.5) & $85(7.9)$ & \\
\hline Current & $536(32.7)$ & $48(8.6)$ & $382(35.5)$ & \\
\hline $\mathrm{BMI}\left(\mathrm{kg} / \mathrm{m}^{2}\right)$ & $23.53 \pm 4.33$ & $22.90 \pm 4.01$ & $23.87 \pm 4.46$ & 0.001 \\
\hline BMI $\left(\mathrm{kg} / \mathrm{m}^{2}\right)$ & & & & $\begin{array}{l}0.001 \\
0.01\end{array}$ \\
\hline underweight (BMl<18.5 kg/m²), n (\%) & 197(12.0) & $70(12.5)$ & $127(11.8)$ & \\
\hline $\begin{array}{l}\text { normal weight (BMI 18.5-23.9 kg/m²), } \\
\text { n (\%) }\end{array}$ & $737(45.0)$ & 291(51.9) & $446(41.4)$ & \\
\hline $\begin{array}{l}\left.\text { overweight (BMI } 24-27.9 \mathrm{~kg} / \mathrm{m}^{2}\right), \mathrm{n} \\
(\%)\end{array}$ & $469(28.6)$ & 153(27.3) & $316(29.4)$ & \\
\hline
\end{tabular}




\begin{tabular}{|c|c|c|c|c|}
\hline obese $\left(\mathrm{BMl} \geq 28 \mathrm{~kg} / \mathrm{m}^{2}\right), \mathrm{n}(\%)$ & $234(14.3)$ & $47(8.4)$ & $187(17.4)$ & \\
\hline neck circumference, $\mathrm{cm}$ & $38.4 \pm 38.5$ & $37.9 \pm 3.3$ & $38.6 \pm 3.6$ & 0.001 \\
\hline FVC & $2.70 \pm 0.94$ & $2.58 \pm 0.90$ & $2.77 \pm 0.96$ & $\begin{array}{l}\square \\
0.001\end{array}$ \\
\hline FEV1, L & $1.41 \pm 0.71$ & $1.29 \pm 0.63$ & $1.48 \pm 0.74$ & $\begin{array}{l}\square \\
0.001\end{array}$ \\
\hline FEV1\%pred & $54.0 \pm 22.5$ & $49.96 \pm 21.54$ & $56.11 \pm 22.78$ & $\begin{array}{l}\square \\
0.001\end{array}$ \\
\hline FEV1/FVC\% & $51.1 \pm 12.8$ & $49.3 \pm 12.5$ & $52.0 \pm 12.8$ & $\begin{array}{l}\square \\
0.001\end{array}$ \\
\hline GOLD stage, $(\mathrm{n}, \%)$ & & & & $\begin{array}{l}\text { D. } \\
0.001\end{array}$ \\
\hline GOLD 1 & $263(16.1)$ & $63(11.2)$ & $200(18.6)$ & \\
\hline GOLD 2 & $575(35.1)$ & 189(33.7) & $386(35.9)$ & \\
\hline GOLD 3 & $569(34.8)$ & $211(37.6)$ & 358(33.3) & \\
\hline GOLD 4 & $230(14.1)$ & $98(17.5)$ & $132(12.3)$ & \\
\hline AHI, events/h & $13.35 \pm 15.09$ & $2.09 \pm 1.46$ & $19.21 \pm 15.65$ & $\begin{array}{l}\square \\
0.001\end{array}$ \\
\hline TS90\% & $12.74 \pm 22.98$ & $8.00 \pm 19.61$ & $15.20 \pm 24.20$ & $\begin{array}{l}\text { D. } \\
0.001\end{array}$ \\
\hline Nadir SaO2, \% & $80.73 \pm 10.97$ & $84.72 \pm 8.46$ & $78.65 \pm 11.54$ & $\begin{array}{l}\text { ] } \\
0.001\end{array}$ \\
\hline Average $\mathrm{SaO} 2, \%$ & $92.84 \pm 3.78$ & $93.61 \pm 3.45$ & $92.44 \pm 3.89$ & $\begin{array}{l}\square \\
0.001\end{array}$ \\
\hline mMRC dyspnea scale score & $1.7 \pm 1.0$ & $1.8 \pm 1.0$ & $1.7 \pm 1.0$ & 0.228 \\
\hline CAT score & $15.4 \pm 7.0$ & $15.7 \pm 7.4$ & $15.2 \pm 6.8$ & 0.945 \\
\hline Hypertension, n(\%) & $657(40.1)$ & $200(35.7)$ & $457(42.5)$ & 0.008 \\
\hline Coronary artery disease, $\mathrm{n}(\%)$ & $255(15.6)$ & $84(15.0)$ & $171(15.9)$ & 0.627 \\
\hline Diabetes n (\%) & 187(11.4) & $62(11.1)$ & $125(11.6)$ & 0.733 \\
\hline
\end{tabular}

Continuous variables were described as means $\pm S D$. Categorical variables were expressed as number(percentages). $\mathrm{P}$ value for the difference between the groups. COPD, chronic obstructive pulmonary disease; OVS, overlap syndrome; BMI, body mass index; GOLD, the global initiative for chronic obstructive lung disease; mMRC dyspnea scale score, modified medical research council dyspnea scale score; CAT score, COPD assessment test score. 
Table 2 The prevalence of diverse severity of OSA in different BMI categories

\begin{tabular}{|c|c|c|c|c|c|}
\hline \multirow{2}{*}{$\begin{array}{l}\text { BMI, Kg/m² } \\
\text { AHI, events/h }\end{array}$} & $\otimes 18.5$ & $\begin{array}{l}18.5- \\
23.9\end{array}$ & & \multirow{2}{*}{$\begin{array}{l}\geq 28 \\
234 \\
(14.3 \%)\end{array}$} & \\
\hline & $\begin{array}{l}197 \\
\square 12.0 \% \rrbracket\end{array}$ & $\begin{array}{l}737 \\
\square 45.0 \% \bigotimes\end{array}$ & $\begin{array}{l}469 \\
\bigotimes 28.6 \% \bigotimes\end{array}$ & & \\
\hline No OSA $\quad \square A H I<5 \rrbracket$ & $70 \rrbracket 35.5 \% \rrbracket$ & $\begin{array}{l}291 \\
\llbracket 39.5 \% \rrbracket\end{array}$ & 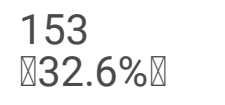 & $47 \rrbracket 20.1 \% \rrbracket$ & 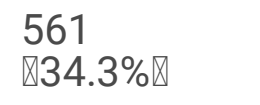 \\
\hline With OSA $\quad \square A H I \geq 5 \rrbracket$ & 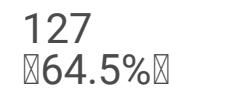 & $\begin{array}{l}446 \\
\bigotimes 60.5 \% \rrbracket\end{array}$ & $\begin{array}{l}316 \\
\otimes 67.4 \% \bigotimes\end{array}$ & $\begin{array}{l}187 \\
\square 79.9 \% \bigotimes\end{array}$ & 1076ه65.7\%区 \\
\hline$x^{2}$ & 0.159 & 16.181 & 0.792 & 24.387 & 30.502 \\
\hline$P$ & 0.690 & $\varangle 0.001$ & 0.374 & $\nabla 0.001$ & $\bowtie 0.001$ \\
\hline No OSA $\quad($ AHIه5) & $70 \rrbracket 35.5 \% \rrbracket$ & $\begin{array}{l}291 \\
\bigotimes 39.5 \% \bigotimes\end{array}$ & $\begin{array}{l}153 \\
\otimes 32.6 \% \bigotimes\end{array}$ & $47 \rrbracket 20.1 \% \rrbracket$ & $561(34.3 \%)$ \\
\hline Mild OSA $\quad(5 \leq \mathrm{AHI} \otimes 15)$ & $91 \rrbracket 46.2 \% \rrbracket$ & $\begin{array}{l}252 \\
\rrbracket 34.2 \% \rrbracket\end{array}$ & 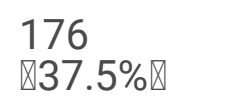 & $72 \bowtie 30.8 \% \rrbracket$ & $591 \rrbracket 36.1 \% \rrbracket$ \\
\hline $\begin{array}{l}\text { Moderate OSA } \quad(15 \leq \mathrm{AHI} \otimes \\
\text { 30) }\end{array}$ & $21 \otimes 10.7 \% \bigotimes$ & 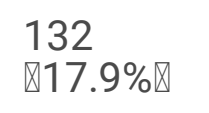 & $86 \rrbracket 18.3 \% \rrbracket$ & $49 \rrbracket 20.9 \% \rrbracket$ & $288 \rrbracket 17.6 \% \rrbracket$ \\
\hline Severe OSA $(A H I \geq 30)$ & $15 \otimes 7.6 \% \rrbracket$ & $62 \rrbracket 8.4 \% \rrbracket$ & $54 \rrbracket 11.5 \% \rrbracket$ & $66 \rrbracket 28.2 \% \rrbracket$ & 197ه12.0\%》 \\
\hline$x^{2}$ & 16.175 & 26.678 & 1.244 & 79.247 & 97.702 \\
\hline$P$ & 0.001 & $\llbracket 0.001$ & 0.742 & $\unrhd 0.001$ & $\bowtie 0.001$ \\
\hline$P$ for trend & 0.011 & $\varangle 0.001$ & 0.729 & $\varangle 0.001$ & $\varangle 0.001$ \\
\hline
\end{tabular}

BMI, body mass index; OSA, obstructive sleep apnea; AHI, apnea hypopnea index.

Table 3 The ORs $(95 \% \mathrm{Cl})$ of dichotomies of BMls for various severity of OSA

\begin{tabular}{|llll|}
\hline BMI, Kg/m2 & Crude & Model 1 & Model 2 \\
AHI, events $/ \mathrm{h}$ & OR $(95 \% \mathrm{Cl})$ & OR $(95 \% \mathrm{Cl})$ & OR $(95 \% \mathrm{Cl})$ \\
& P value & P value & P value \\
\hline
\end{tabular}




\begin{tabular}{|c|c|c|c|}
\hline $\begin{array}{l}\text { Risk for OSA } \\
(\mathrm{AHI} \geq 5)\end{array}$ & & & \\
\hline BMI $₫ 18.5$ (underweight) & $\begin{array}{l}0.939(0.687- \\
1.282)\end{array}$ & $\begin{array}{l}1.128(0.819- \\
1.555)\end{array}$ & $\begin{array}{l}1.234(0.888- \\
1.713)\end{array}$ \\
\hline & 0.690 & 0.460 & 0.210 \\
\hline $18.5 \leq \mathrm{BMI} \otimes 24.0$ (normal weight) & $\begin{array}{l}0.657(0.535- \\
0.807)\end{array}$ & $\begin{array}{l}0.688(0.559- \\
0.847)\end{array}$ & $\begin{array}{l}0.670(0.542- \\
0.828)\end{array}$ \\
\hline & $\otimes 0.001$ & $₫ 0.001$ & $₫ 0.001$ \\
\hline $24.0 \leq \mathrm{BMI} \otimes 28.0$ (overweight) & $\begin{array}{l}1.109(0.883- \\
1.392)\end{array}$ & $\begin{array}{l}1.011(0.802- \\
1.275)\end{array}$ & $\begin{array}{l}0.989(0.782- \\
1.251)\end{array}$ \\
\hline & 0.374 & 0.924 & 0.927 \\
\hline $\mathrm{BMI} \geq 28$ & $\begin{array}{l}2.300(1.641- \\
3.225)\end{array}$ & $\begin{array}{l}2.090(1.486- \\
2.941)\end{array}$ & $\begin{array}{l}2.179(1.531- \\
3.100)\end{array}$ \\
\hline (UNCSC) & $\otimes 0.001$ & $₫ 0.001$ & $\triangle 0.001$ \\
\hline $\begin{array}{l}\text { Risk for moderate-to-severe OSA } \\
\text { (AHI } \geq 15)\end{array}$ & & & \\
\hline BMI $ه 18.5$ (underweight) & $\begin{array}{l}0.494(0.338- \\
0.720)\end{array}$ & $\begin{array}{l}0.586 \rrbracket 0.398- \\
0.862 \rrbracket\end{array}$ & $\begin{array}{l}0.633(0.428- \\
0.938)\end{array}$ \\
\hline & $\varangle 0.001$ & 0.007 & 0.023 \\
\hline $18.5 \leq \mathrm{BMI} \otimes 24.0$ (normal weight) & $\begin{array}{l}0.748(0.603- \\
0.927)\end{array}$ & $\begin{array}{l}0.789(0.634- \\
0.981)\end{array}$ & $\begin{array}{l}0.787(0.629- \\
0.985)\end{array}$ \\
\hline & 0.008 & 0.033 & 0.036 \\
\hline $24.0 \leq \mathrm{BMI} \otimes 28.0$ (overweight) & $\begin{array}{l}1.015(0.803- \\
1.283)\end{array}$ & $\begin{array}{l}0.915(0.720- \\
1.163)\end{array}$ & $\begin{array}{l}0.887(0.695- \\
1.132)\end{array}$ \\
\hline & 0.900 & 0.470 & 0.334 \\
\hline $\mathrm{BMI} \geq 28$ & $\begin{array}{l}2.698(2.034- \\
3.579)\end{array}$ & $\begin{array}{l}2.465(1.852- \\
3.282)\end{array}$ & $\begin{array}{l}2.595(1.916- \\
3.515)\end{array}$ \\
\hline (UNCSC) & $\otimes 0.001$ & $\varangle 0.001$ & $\varangle 0.001$ \\
\hline Risk for severe OSA (AHI $\geq 30)$ & & & \\
\hline BMI $ه 18.5$ (underweight) & $\begin{array}{l}0.570 \rrbracket 0.329- \\
0.986 \rrbracket\end{array}$ & $\begin{array}{l}0.705 \rrbracket 0.403- \\
1.234 \rrbracket\end{array}$ & $\begin{array}{l}0.805(0.455- \\
1.423)\end{array}$ \\
\hline & 0.045 & 0.221 & 0.455 \\
\hline 18.5 $\leq \mathrm{BMI} \otimes 24.0$ (normal weight) & $\begin{array}{l}0.520(0.379- \\
0.715)\end{array}$ & $\begin{array}{l}0.551(0.400- \\
0.759)\end{array}$ & $\begin{array}{l}0.582(0.419- \\
0.809)\end{array}$ \\
\hline & $\varangle 0.001$ & $\varangle 0.001$ & 0.001 \\
\hline
\end{tabular}




\begin{tabular}{|c|c|c|c|}
\hline \multirow[t]{2}{*}{$24.0 \leq \mathrm{BMI} \otimes 28.0$ (overweight) } & $\begin{array}{l}0.933(0.668- \\
1.301)\end{array}$ & $\begin{array}{l}0.827(0.589- \\
1.161)\end{array}$ & $\begin{array}{l}0.789(0.559- \\
1.113)\end{array}$ \\
\hline & 0.682 & 0.273 & 0.177 \\
\hline \multirow{2}{*}{$\begin{array}{c}\text { BMI } \geq 28 \\
\text { (obese) }\end{array}$} & $\begin{array}{l}3.815(2.724- \\
5.342)\end{array}$ & $\begin{array}{l}3.474(2.470- \\
4.887)\end{array}$ & $\begin{array}{l}3.356(2.328- \\
4.837)\end{array}$ \\
\hline & $\otimes 0.001$ & $\mathbb{\nabla} 0.001$ & $\varangle 0.001$ \\
\hline
\end{tabular}

BMI, body mass index; OSA, obstructive sleep apnea; AHI, apnea hypopnea index; OR, odds ratio. Crude, no adjustment; Model 1, adjusted for $\mathrm{FEV}_{1} \%$ pred; Model 2, adjusted for sex, age, job, education, smoking, alcohol consumption, $\mathrm{FEV}_{1} \%$ pred, and high blood pressure.

Table 4 ORs ( $95 \% \mathrm{Cl})$ of varying severity of OSA according to BMls in COPD

\begin{tabular}{|lllll|}
\hline BMI, Kg/m2】 & AHI, events/h & $\begin{array}{l}\text { Crude } \\
\text { OR }(95 \% \mathrm{Cl})\end{array}$ & $\begin{array}{l}\text { Model 1 } \\
\text { OR }(95 \% \mathrm{Cl})\end{array}$ & OR (95\%Cl) \\
& P value & P value & P value \\
BMI with OSA & & & \\
$(\mathrm{AHI} \geq 5)$ & & & \\
\hline
\end{tabular}




\begin{tabular}{|c|c|c|c|}
\hline \multirow[t]{2}{*}{ BMIه18.5 (underweight) } & $\begin{array}{l}1.184(0.854- \\
1.642)\end{array}$ & $\begin{array}{l}1.328(0.952- \\
1.851)\end{array}$ & $\begin{array}{l}1.424(1.015- \\
1.998)\end{array}$ \\
\hline & 0.312 & 0.095 & 0.041 \\
\hline \multirow[t]{2}{*}{$18.5 \leq \mathrm{BMI} \otimes 24.0$ (normal weight) } & 1.000 (Ref) & 1.000 (Ref) & 1.000 (Ref) \\
\hline & - & - & - \\
\hline \multirow[t]{2}{*}{ 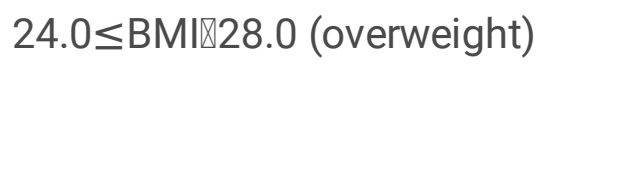 } & $\begin{array}{l}1.348(1.057- \\
1.718)\end{array}$ & $\begin{array}{l}1.241(0.969- \\
1.588)\end{array}$ & $\begin{array}{l}1.254(0.974- \\
1.613)\end{array}$ \\
\hline & 0.016 & 0.087 & 0.079 \\
\hline \multirow[t]{2}{*}{$\mathrm{BMI} \geq 28$ (obese) } & $\begin{array}{l}2.596(1.825- \\
3.692)\end{array}$ & $\begin{array}{l}2.333(1.633- \\
3.332)\end{array}$ & $\begin{array}{l}2.468(1.704- \\
3.574)\end{array}$ \\
\hline & $₫ 0.001$ & $\varangle 0.001$ & $\varangle 0.001$ \\
\hline$P$ for trend & 0.002 & $₫ 0.001$ & 0.001 \\
\hline \multicolumn{4}{|l|}{$\begin{array}{l}\text { BMI with moderate-to-severe OSA } \\
(A H I \geq 15)\end{array}$} \\
\hline \multirow[t]{2}{*}{ BMIه18.5 (underweight) } & $\begin{array}{l}0.626(0.421- \\
0.931)\end{array}$ & $\begin{array}{l}0.697(0.466- \\
1.041)\end{array}$ & $\begin{array}{l}0.733(0.488- \\
1.100)\end{array}$ \\
\hline & 0.021 & 0.078 & 0.134 \\
\hline \multirow[t]{2}{*}{$18.5 \leq \mathrm{BMI} \otimes 24.0$ (normal weight) } & 1.000 (Ref) & 1.000 (Ref) & 1.000 (Ref) \\
\hline & - & - & - \\
\hline \multirow[t]{2}{*}{ 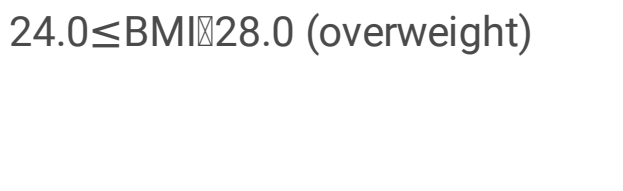 } & $\begin{array}{l}1.191(0.921- \\
1.540)\end{array}$ & $\begin{array}{l}1.100(0.847- \\
1.428)\end{array}$ & $\begin{array}{l}1.109(0.849- \\
1.449)\end{array}$ \\
\hline & 0.182 & 0.475 & 0.447 \\
\hline \multirow[t]{2}{*}{$\mathrm{BMI} \geq 28$ (obese) } & $\begin{array}{l}2.705(1.995- \\
3.667)\end{array}$ & $\begin{array}{l}2.461(1.807- \\
3.350)\end{array}$ & $\begin{array}{l}2.642(1.902- \\
3.670)\end{array}$ \\
\hline & $\bowtie 0.001$ & $凶 0.001$ & $₫ 0.001$ \\
\hline$P$ for trend & $\bowtie 0.001$ & $₫ 0.001$ & 0.001 \\
\hline \multicolumn{4}{|l|}{ BMIs with severe OSA $(\mathrm{AHI} \geq 30)$} \\
\hline \multirow[t]{2}{*}{ BMIه18.5 (underweight) } & $\begin{array}{l}0.897(0.499- \\
1.614)\end{array}$ & $\begin{array}{l}1.017(0.562- \\
1.842)\end{array}$ & $\begin{array}{l}1.076(0.591- \\
1.958)\end{array}$ \\
\hline & 0.718 & 0.955 & 0.811 \\
\hline \multirow[t]{2}{*}{$18.5 \leq \mathrm{BMI} \otimes 24.0$ (normal weight) } & 1.000 (Ref) & 1.000 (Ref) & 1.000 (Ref) \\
\hline & - & - & - \\
\hline $24.0 \leq$ BMI $₫ 28.0$ (overweight) & $\begin{array}{l}1.417(0.964- \\
2.081)\end{array}$ & $\begin{array}{l}1.297(0.878- \\
1.914)\end{array}$ & $\begin{array}{l}1.258(0.847- \\
1.870)\end{array}$ \\
\hline
\end{tabular}




\begin{tabular}{|c|c|c|c|}
\hline & 0.076 & 0.191 & 0.256 \\
\hline \multirow[t]{2}{*}{$\mathrm{BMI} \geq 28$ (obese) } & $\begin{array}{l}4.277(2.908- \\
6.290)\end{array}$ & $\begin{array}{l}3.861(2.612- \\
5.708)\end{array}$ & $\begin{array}{l}3.741(2.463- \\
5.682)\end{array}$ \\
\hline & $\otimes 0.001$ & $\otimes 0.001$ & $\otimes 0.001$ \\
\hline$P$ for trend & $\otimes 0.001$ & $\otimes 0.001$ & 0.001 \\
\hline
\end{tabular}

BMI, body mass index; OSA, obstructive sleep apnea; AHI, apnea hypopnea index; OR, odds ratio. Crude, no adjustment; Model 1, adjusted for $\mathrm{FEV}_{1} \%$ pred; Model 2, adjusted for sex, age, job, education, smoking, alcohol consumption, $\mathrm{FEV}_{1} \%$ pred, and high blood pressure.

\section{Figures}

\section{Individuals with a diagnosis of COPD}

$$
\mathrm{n}=1911
$$

Exclusion of individuals with refused PSG $\mathrm{n}=161$ (Included 77 cases who lack spirometry data too)

Exclusion of individuals who did not complete lung function test $\mathrm{n}=128$

Exclusion due data unqualified $\mathrm{n}=62$

\section{Individuals in final analysis}

$$
\mathrm{n}=1637
$$

\section{Figure 1}

Flow of participants through the study. COPD, chronic obstructive pulmonary disease. PSG, polysomnography. 

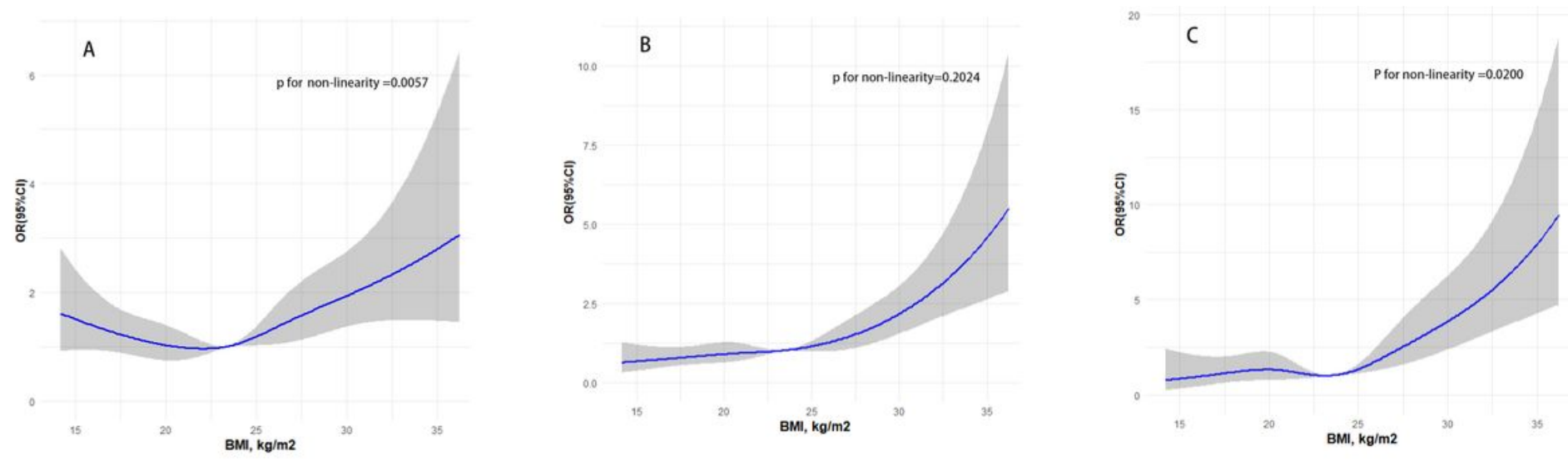

\section{Figure 2}

Association between BMI and risks of varying severity of OSA in COPD patients. Estimates adjusted for sex, age, job, education, smoking, alcohol consumption, FEV1\%pred, and high blood pressure. The dashed area represents the $95 \% \mathrm{Cl}$. BMI, body mass index. OR, odds ratio. 